\title{
O gênio e as novas formas de representação cinematográfica do sujeito de conhecimento.
}

\author{
The genius and the new forms of cinematic representation of the subject of \\ knowledge
}

\author{
Fábio de Godoy Del Picchia Zanoni ${ }^{1}$
}

RESUMO

Objetivando problematizar as novas formas de representação cinematográfica do gênio, o presente artigo, amparado no legado teórico-metodóligoco de Michel Foucault, interpela os efeitos, em operação na contemporaneidade, da circulação social de novas figuras do sujeito de conhecimento, salientando, desta feita, os pressupostos silenciosos que tendem a informar o modo pelo qual os espectadores podem e devem imaginar a si e aos outros como sujeitos capazes de produção de modalidades de saber-fazer específicas. Para tanto, o presente artigo apoia-se em uma plataforma empírica que conta com quatro filmes: Meu pé esquerdo (1989), Gênio Indomável (1997), Billy Elliot (2000) e Encontrando Forrester (2000).

Palavras-chave: Cinema. Sujeito do Conhecimento. Foucault.

ABSTRACT

Aimed at questioning new forms of cinematic representation of the genius, this article, in the wake of Foucault's theories, seeks to extend the understanding of the effects, operatting in contemporarily, of the social circulation of new figures of the subject of knowledge, emphasizing, thus, the silent assumptions that have come to inform the way in which viewers can and should imagine themselves and others as subjects capable of producing specific modalities of know-how. Therefore, this article relies on an empirical platform consisting of four films: My left foot (1989), Good Will Hunting (1997), Billy Elliot (2000) and Finding Forrester (2000).

Keyword: Cinema. Subject of Knowledge. Foucault.

${ }^{1}$ Doutor em História da Educação. 


\title{
1 Introdução
}

\begin{abstract}
Eu diria que a primeira coisa que se deveria aprender - se tem sentido aprender algo assim - é que o saber está profundamente ligado ao prazer. Certamente há uma maneira de erotizar o saber, torná-lo altamente agradável. Que o ensino não seja capaz de revelar isso, que tenha como função mostrar o quanto o saber é desagradável, triste, cinza, pouco erótico, é uma tarefa que exige enorme esforço. Mas esse esforço tem certamente sua razão de ser. Seria preciso saber por que nossa sociedade tem tanto interesse em mostrar que o saber é triste. Talvez precisamente por causa do número de pessoas que dele são excluídas (Michel Foucault).
\end{abstract}

De modo genérico, podemos afirmar que os trabalhos inspirados nas reflexões de Michel Foucault tendem a bifurcar-se por dois caminhos: o primeiro deles privilegiaria a investigação dos mecanismos, procedimentos e práticas constritivas a partir das quais as condutas dos sujeitos são informadas - as figuras do outro constituem seus temas principais. O segundo caminho possível incidiria nas formas produtivas de problematização de si que permitem e convocam os sujeitos, em determinado período histórico, a se elaborarem e transformarem em vista de se tornarem um determinado tipo de ser. O presente artigo é, sobretudo, tributário da segunda forma de problematização.

Isso significa que não me interessa a abordagem do cinema stricto sensu. Aqui, os filmes selecionados despontam tão somente e tanto como um dos laboratórios sociais de produção de formas de representação do sujeito de conhecimento que incitam a fabricação de modalidades específicas de experiências do espectador consigo. Dito de modo simples, alardeei o estreito vínculo entre os tipos de relação com os saberes ofertados em um determinado momento histórico e as imagens do que são/seriam os sujeitos de conhecimento na ótica de certas narrativas fílmicas hollywoodianas. Sumarizando: ao tomar o cinema como aporte empírico, sobretudo por conta de seu papel de arte de massas (BENJAMIN, 1996), cujo enorme poder de difusão de ideais reguladores é notório, pretendi perspectivar o cinema sob o signo da governamentalidade (FOUCAULT, 2006, p.281). Sob esse crivo, as identidades evocadas pelos espectadores de cinema para darem forma à relação de si a si não são nunca sentidas como o resultado de uma descoberta individual, mas sim como construções sociais que os convocam ao exercício de determinado tipo de trabalho sobre si, a fim de se conduzirem de acordo com o tipo de gente que acreditam ser. Nas palavras do historiador Jorge Ramos do Ó:

Identificando seu nome com o nome de um sujeito particular, o ser humano está afinal a trabalhar sobre um conjunto de alter identificações. Escolho quase ao acaso 
algumas definições diferenciadoras ou categorias de ser: branco, mulher, aluno, anormal, homossexual, etc. São essas e outras identidades hegemônicas que estão na origem da relação do indivíduo consigo próprio, nos tipos de disposições e hábitos que vai inculcando. Podemos dizer que é por esse caminho que a governamentalidade vai se inscrevendo no corpo dos homens. (RAMOS DO Ó, 2003, p.38).

Mas mais e tais: é necessária a ressalva de a eleição do cinema como solo empírico de análise não se explicar apenas por seu poder imperialista de irradiação de ideais reguladores, mas também, e sobretudo, socorre-me o fato de o cinema, entendido como instrumento de pedagogia informal (SMEYERS; DEPAEPE, 2008), constituir instrumento de governo diligente e pujante em tempos de liberalismo. Explico-me. Ao legitimar sua prática como um modo de governo que não tolera excessos de intervenções do Estado em nome da liberdade dos sujeitos, o liberalismo deixa de governar simplesmente por leis, decretos e imposições. O que cria para si o seu maior imbróglio: como não governar abusivamente sem, contudo, deixar de governar? É aqui que a agilidade política do cinema ganha todo seu sentido. Atribuindo-se um caráter não político, nomeadamente se fazendo passar por mero entretenimento (NEVES, 2006), as narrativas cinematográficas afastam-se os órgãos formais do poder e os sistemas de regulação do eu, conquistando, desse modo, livre acesso a zonas onde o Estado não poderia alcançar sem comprometer a suposta autonomia dos cidadãos.

Assim, a crucial importância das narrativas cinematográficas na contemporaneidade residiria em sua competência em transformar certas imagens do sujeito de conhecimento em uma escolha que teria nas fronteiras do sujeito sua única origem. Para dizer o menos, diria que o que está em jogo é o fato de que, se o «governamento liberal»(VEIGA-NETO, 2002, p.13-34), só poderá ocorrer de maneira indireta, se administrar os cidadãos em um contexto liberal significará governá-los conforme seu livre-arbítrio, suas escolhas deverão alinhar-se com as expectativas estatais. Eis o motivo pelo qual Foucault insistia na problematização de instituições sociais que se mostravam apartadas de todo e qualquer poder político:

Parece-me que numa sociedade como a nossa, a verdadeira tarefa política é a de criticar o jogo das instituições aparentemente neutras e independentes; criticá-las e atacá-las de tal maneira que a violência política que se exercia obscuramente nelas seja desmascarada e que se possa lutar contra elas. (FOUCAULT, 2006, p.114).

Acrescento tento, pois é vital esclarecer o que entendo por representações. Ao falar delas no cinema, não tenho em mente uma adequação entre as cenas as coisas. Aqui, o papel da linguagem cinematográfica não jaz na capacidade de espelhamento do mundo, radica em sua destreza de modificá-lo e produzi-lo indefinidamente. Acertando meus passos com os de Jorge Larossa (1994, p. 28), afirmaria que: 


\begin{abstract}
o discurso não admite nenhuma soberania exterior a si mesmo. Nem a de um mundo de coisas da qual seria uma representação secundária, nem a de um sujeito que seria sua fonte ou sua origem. Pelo contrário, o discurso é condição de possibilidade tanto do mundo de coisas quanto da constituição de um falante singular ou de uma comunidade de falantes.
\end{abstract}

Assim, em lugar de descortinar a alegada realidade que subjazeria à dispersão dos discursos cinematográficos, preferi atentar aos protocolos discursivos mobilizados na criação da figura do gênio.

Do ponto de vista da história do cinema, raramente os afazeres estéticos se viram desenhados como portadores de efeitos positivos sobre a conduta das personagens. Penso em três exemplos.

Conforme já referido, em 1959, nO Crepúsculo dos Deuses, Norma Desmond confina-se em uma erma mansão, à espera da loucura, tendo sido aposentada a contragosto pelo cinema falado, depois de estrelar no mudo. NA noite dos desesperados, de 1969, a sina dos geniais é selada no tablado de uma maratona de dança em que os mais pobres, assolados pela Grande Depressão estadunidense, engalfinham-se pelo prêmio de US $\$ 1,5$ mil. Já em 1975, em Três dias do Condor, as narrativas literárias assomam perigos radicais, capitaneando assassinatos de agentes da Central Intelligence Agency (CIA).

Sem dúvida muito esquemático, este introito apenas demonstra como, antes da década de 1980, conectar o saber (no caso, artístico) aos proveitos para o sujeito que dele se apropriara (o gênio), fossem eles sociais, políticos, cognitivos, afetivos ou éticos, não se assentava consenso no universo cinematográfico estadunidense, longe disso. Situo apenas em 1989, a partir do filme Meu pé esquerdo, certa emergência da veiculação desses nexos produtivos, afirmativos, alegres, estimulando diferentes estratégias de erotização do saber ${ }^{2}$.

\title{
2. Meu pé esquerdo
}

Na primeira cena do filme, que é também a final - já que o filme é contado retrospectivamente -, Christy Brown, o pintor e escritor cuja paralisia física Ihe reserva apenas o movimento do pé esquerdo, chega com sua família a uma mansão, na qual Ihe será prestada uma homenagem pela autobiografia recém publicada. O livro

${ }^{2}$ Filmes como $O$ despertar de Rita (1983) já esboçavam conexões potentes entre a arte e as outras instâncias sociais. No entanto, via de regra, ao final de sucessivos processos de emancipação, essas personagens tornavam-se leitoras, alfabetizadas fluentes, nunca produtoras. 
tem início com o passado de Brown. E é para lá que o filme nos leva. Logo nas primeiras cenas de sua infância, o problema da dependência gerada pela deficiência física vem à baila. A mãe do escritor sobe as escadas da casa carregando o filho às costas. E sofre um infarto. Filho de uma família irlandesa pobre, Brown pode não ter tido as condições materiais adequadas para o enfrentamento de sua deficiência, mas não lhe faltara bemquerer, visto que o gesto materno beira o sacrifício.

Ainda que possa despertar alguma compaixão no espectador, a tragicidade da infância do escritor não se aloja na dependência resultante da deficiência vivida em uma atmosfera de pobreza, mas na falta de compreensão daqueles que estão à sua volta. Se a pobreza origina uma máxima proximidade entre os familiares (os filhos dormem juntos, alimentam-se da mesma comida, vestem do mesmo macacão), a deficiência cava distâncias, traduzidas na manufatura de um mundo interior inacessível aos demais, como se a fusão e o abismo coexistissem na experiência da deficiência em ambientes de carência material. Muito mais que a paralisia física, é a afasia do escritor em seus tempos de meninice que aflige o espectador.

Prova disso é o fato de a queda da intensidade das agulhadas da aflição que acossam os espectadores em virtude da situação de Brown ocorrer justamente no momento em que o menino consegue provar que deflui vida inteligente dentro de si, ao escrever no chão com um pequeno pedaço de giz entre os dedos a palavra mother. Inteligência que, para nós, não é fonte de surpresa. No máximo, de alivio. Ao contrário do pai do escritor, que via no filho uma criatura desprovida de qualquer inteligência, ao contrário da mãe que, não obstante a enorme devoção para com Brown, supunha que apenas Deus poderia compreender seu rebento, nós, os espectadores, devido ao caráter retrospectivo do filme, já sabíamos das capacidades do menino afásico. Atalhando: o que me interessa, nesse passo da narrativa, é reter a emergência de um dispositivo narrativo absolutamente fundamental para as novas perspectivações cinematográficas do gênio, a saber, o da genialidade latente, isto é, a produção de um modo de ser da personagem que se caracteriza por portar tesouros que, em razão de obstáculos físicos, sociais ou psicológicos, não podem à partida granjear às luzes da ribalta.

Em seguida, o filme salta para a adolescência do escritor/pintor. À parte as diferenças físicas, Brown conduz uma vida idêntica à dos demais, inserido de corpo e alma na vida comunitária, tanto tomando parte do futebol de rua quanto participando dos jogos amorosos. Ora, associado a uma figura com notáveis dificuldades de socialização, a arte não figura, sob hipótese alguma, como princípio indutor de solidão. Tornase inevitável que suceda o inverso. Ela, a arte, intervém a título de meio indispensável na consecução de duas metas distintas e complementares: a ascensão social e a realização do amor. Porém, as habilidades já conquistadas por Brown só têm chance de render estes e outros frutos a partir do momento em que surge uma autoridade especializada, no caso, uma médica, que o assessora no aprimoramento da sua articulação verbal, a fim de ele não mais depender da mediação da mãe para ser compreendido. Ao cabo e ao fim, já alfabetizado na arte da verbalização e tendo auferido de única tacada rendimento que seu pai costumava acumular no período de um ano, o artista casa e despede-se da mãe. 


\section{Gênio Indomável}

Na década seguinte, mais precisamente em 1997, entra em cartaz um filme que retoma e consolida, não sem severas inflexões, os dispositivos narrativos do filme acima analisado, dispositivos que ganharão, então, a particularidade de erotizar o saber mais em virtude do poder sobre o outro que em nome das transformações sobre si.

Da mesma maneira que Brown, também Will Hunting, a nova figura do gênio, procede de extrema pobreza, situada no Bronx, bairro pobre de New York. Tal o pintor, cujos empecilhos físicos obrigavam-no a lutar para sair do canto da sala debaixo da escada onde se atracava constantemente, também o sagaz matemático, bloqueado por âncoras psicológicas, não pode expandir seu território de circulação social sem o corte com os mecanismos de tração que entravam o usufruto dos mais variados cais da vida em sociedade.

Se o perímetro de circulação de Brown restringia-se à casa e à família antes da intervenção da médica, Will transita tão somente entre a própria casa, algum lazer esportivo e um ou dois bares, sempre na companhia dos três únicos amigos. Acontece que, devido ao seu ímpeto violento, Will restringe ainda mais sua mobilidade no tecido social. Após se envolver em uma briga, ele é encarceirado, imediatamente a seguir ao encontro com Skylar, a mulher por quem se apaixona. Ora, a fim de conquistar sua liberdade, bem como a possibilidade de vivenciar o amor, Will terá de aprender a falar, dado que seus sucessivos pais adotivos, que o maltrataram fisicamente quando menino, deformaram seu corpo subjetivo, que passou a não se locomover socialmente sem o auxílio da muleta da violência.

É quando entra em cena Sean Maguire, o psicólogo, quem se encarregará da ortopedia da alma do gênio imberbe. Will pacificar-se-á daí em diante, escanteando a violência, até se tornar um cidadão capaz de amar e ascender socialmente - ascensão que se consubstancia não mais no acesso às mansões, mas às empresas e aos centros de inteligência militar. Não é à toa que, somente depois da decisão de falar com o psicólogo, abdicando do mutismo das primeiras sessões, Will dá início ao relacionamento com Skylar (cenas antes, Will tinha arriscado uma ligação de um orelhão para a amada, mas havia desligado sem dizer palavra, evidenciando a dificuldade de expressar-se).

Todavia, a superação das deficiências de Will nada tem que ver com os doze trabalhos de Hércules levados a efeito pelo pintor acometido de paralisia física. Ainda que haja semelhanças, a tônica do processo de Brown recaía sobre a superação de si, ao passo que o filme de Gus Van Sant vinca a superação sobre o outro - o professor acadêmico, a mulher amada, inclusive os amigos. E isso porque, na curvatura do perfil do novo gênio, não há espaço para a aprendizagem. Sempre com facilidade, Will realiza problemas matemáticos que os alunos demorariam semestres inteiros para solucionar, que os professores levaram «more than two years to prove», chegando mesmo a deixar o professor de matemática, Gerald Lambeau, de joelhos, desesperado para salvar das chamas os restos do pedaço de papel em que Will havia resolvido problemas matemáticos, antes de atear fogo nele. Além disso, Will também esmaga as pretensões esnobes de saber de um garoto petulante de Harvard que tenta fazer chacota de seu amigo Chuckie, um rapaz que, mesmo destituído da bossa dos 
gênios, tenta se passar por estudante, no intuito de conquistar a atenção de duas garotas no bar. Como se isso não bastasse, Will resolve, em um piscar de olhos, problemas de química orgânica que a namorada se desunha para compreender, sem contar que conhece com mais precisão e acuidade sobre advocacia do que o advogado engravatado que o condena à prisão. Pelo saber avantajado que possui, o gênio indomável reina, pois, em todos os campos da vida social, ainda que adote a postura de um déspota esclarecido, que só mostra os dentes quando ele, ou algum dos seus protegidos, é ameaçado³.

O poder soberano do gênio não poupa sequer os amigos. No entanto, o esmagamento dos amigos não se faz de maneira explícita. Não é Will quem decide pela solitária ascensão social. Inclusive, ele havia manifestado o desejo de permanecer até o fim dos seus dias no mesmíssimo patamar social de seus camaradas:

Chuckie: Are they hookin you up with a job?

Will: Yeah, sit in a room and do long division for the next fifty years.

Chuckie: Probably make some nice bank, though.

Will: I'm gonna be a fuckin lab rat.

Chuckie: Better than this shit. It's a way out of here.

Will: Why do I want to go out of here? I mean, I'm gonna fuckin live here the rest $\mathrm{f}$ my life. You know, we'll be neighbour's, we'll have little kids and fucking take them to little league together up at Foley field.

Chuckie: Look, you're my best friend, so don't take this the wrong way. In twenty years, if you're still living here, coming over to my house to watch the Patriots games, still working in construction, I'll fuckin' kill you. That's not a threat. That's a fact. I'll fuckin' kill you. ${ }^{4}$

\footnotetext{
3 Como tentei argumentar em outra ocasião (ZANONI, 2012), a legitimação da representação das maiores violências no cinema, sobretudo a partir da década de 1950, passou a ser obrada em nome da defesa de si e do outro, nunca em nome da vingança. 4 Tradução:

Chuckie: Eles estão te arrumando um emprego?Will: Sim, sentar em uma sala e fazer longas contas de divisão pelos próximos cinquenta anos. Chuckie: Provavelmente vai fazer uma boa conta no banco, apesar de tudo. Will: Eu vou ser uma merda de um rato de laboratório.

Chuckie: Melhor do que esta merda. É um jeito de sair daqui.Will: Por que eu sairia daqui? Quer dizer, eu vou viver aqui nessa porra o resto da minha vida. Você sabe, nós vamos ser vizinhos, vamos ter crianças pequenas e vamos levá-las juntos para a porra dos jogos da Liga Júnior no campo de Foley.

Chuckie: Olha, você é meu melhor amigo, portanto, não tome isso da maneira errada. Em vinte anos, se você ainda estiver vivendo aqui, vindo para minha casa para ver os jogos dos Patriots, trabalhando em construção, eu mato você, porra. Isso não é uma ameaça. Isso é um fato. Mato você, porra.
} 
Apanhamos o fundamental. Preciso atravessar nossa atenção o fato de os domínios de saber em que Will exubera - a matemática, a advocacia, a química orgânica - serem absolutamente ininteligíveis para a esmagadora maioria dos espectadores (eu, por exemplo, sequer sei se os números rabiscados na lousa representam equações matemáticas reais ou enfeites cênicos). Dito de outro modo, o que nos emociona não é o produto da genialidade de Will - não estamos diante dos quadros de Van Gogh do filme Vincent \& Theo. O que nos emociona é o poder de esmagamento do outro que a figura do gênio é capaz, ainda que esse excesso de poder custe a vilanização das figuras pisoteadas pelo gênio. O ponto é este: quando nos identificamos com as peripécias de Will Hunting, não temos empatia pela criação de um objeto qualquer - matemático, artístico ou jurídico. Bem vistas as coisas, estamos sequiosos pelo exercício de uma forma de poder baseada no monopólio exclusivo de um saber misterioso. Ora, o escondimento das operações cognitivas do gênio só é possível, a meu ver, pela ausência de filiações intelectuais durante a exibição dos malabarismos cognitivos do gênio, um tipo de endereçamento ao saber prescrito, aliás, pelo próprio psicólogo:

Sean: So if I asked you about art, you'd probably give me the skinny on every art book ever written. Michelangelo? You know a lot about him. Life's work, political aspiration, sexual orientation. The whole works, right? I bet you can't tell me what it smells like in the Sistine Chapel. You never actually stood there and looked up at that beautiful ceiling. Seeing that. If I ask you about women, you'll probably give me a syllabus of your personal favourites. You may have even been laid a few times. But you can't tell me what it feels like to wake up next to a woman... and feel truly happy (...) If I ask you about war, you'd probably throw Shakespeare at me, right? "Once more into the breach, dear friends." But you've never been near one. You've never held your best friend's head in your lap... and watched him gasp his last breath looking to you for help. If I asked you about love, you'd probably quote me a sonnet, but you've never looked at a woman and been totally vulnerable (...) I look at you. I don't see an intelligent, confident man. I see a cocky, scared shitless kid. But you're a genius, Will. No one denies that. No one could possibly understand the depths of you (...) You're an orphan, right? Do you think that l'd know the first thing about how hard your life has been - how you feel, who you are - because I read Oliver Twist? Does that encapsulate you? Personally, I don't give a shit about all that, because - You know what? I can't learn anything from you... I can't read in some fuckin' book. Unless you wanna talk about you, who you are. And I'm fascinated. I'm in. But you don't wanna do that, do you sport? You're terrified of what you might say. ${ }^{5}$

5 Tradução:

Sean: Então, se eu lhe perguntar sobre arte, você provavelmente me daria a descrição de cada livro de arte já escrito. Michelangelo? Você sabe muito sobre ele. $O$ trabalho que realizou na vida, as aspirações políticas, a orientação sexual, toda a obra, certo? Aposto que você não pode me dizer como é o cheiro da Capela Sistina. Você nunca esteve realmente lá e olhou para aquele teto lindo, vendo-o (de fato aquilo). Se eu lhe perguntar sobre mulheres, você provavelmente me dará uma lista das suas favoritas. Você pode até já ter dormido com mulheres algumas vezes. Mas você não pode me dizer o que acordar ao lado de uma mulher e se sentir verdadeiramente feliz (...) Se eu lhe perguntar sobre guerra, você provavelmente jogaria Shakespeare em mim, certo? «Uma vez mais para a ponte, queridos amigos». Mas você nunca esteve perto de uma. Você nunca segurou a cabeça do seu melhor amigo no 
A orfandade de Will não está aí à toa. Ela atesta que o gênio foi privado de heranças. Isto dito, importa reter o fulcral: o gênio terá de ser convertido em origem da própria discursividade. Para tanto, a exclusão da família não é, da missa, um terço. Em igual medida, cumpre varrer do mapa mental do espectador todo e qualquer sistema de remissão que religasse o gênio ao patrimônio social em geral. Daí, a leitura de Shakespeare surgir a título de obstáculo do desenvolvimento psicológico de Will. Como é evidente, não se trata de desqualificação global dos saberes pretéritos, até porque a legitimidade das intervenções do psicólogo depende deles. Antes, trata-se da introdução de princípios que permitam conferir um valor de matriz virginal ao pensamento individual de Will. De modo que, no afã de fincar bases pessoais para o florescimento do pensamento do jovem matemático, o psicólogo, em vez de alegrar-se com o fato de uma pessoa pobre ter podido gozar de uma longa convivência com saberes amiúde reservados às elites, transforma-os em obstáculo maior de uma vida plena - ressalva feita aos saberes que podem ser reinscritos em circuitos financeiros (o professor de matemática não se cansa de agendar entrevistas de trabalho ao jovem Will).

Portanto, é a própria figura de autoridade que decreta o fim da referenciação aos saberes como condição incontornável para uma vida que se regularia pelo contato imediato com os objetos. Obviamente, esse silenciamento não implica ausência de qualquer conversação entre o gênio e as outras personagens. As experiências privadas do indivíduo Will podem e devem ser assaz eloqeentes. Nunca as do gênio Will. Neste caso, a afasia é total. Se Will passa a ter longos diálogos no divã, ele não é capaz de responder satisfatoriamente a Skylar se a sua genialidade é ou não o resultado de uma "photographic memory». Se o mais brilhante dos matemáticos diz tão pouco sobre os próprios processos de trabalho, se ele mesmo declara a impossibilidade de relato da viagem intelectual na qual embarca na solução dos seus problemas matemáticos, não seria absurdo que outras personagens, bem como os espectadores, pensassem o contrário? Sem sombra de dúvida, esta é a força da modéstia do gênio: ao renunciar a falar sobre o processo de produção de seu pensamento, Will desarma as controvérsias acerca do caráter inefável que supostamente caracterizaria suas operações intelectuais.

Ligando os pontos: quando se aproximam de Will, as personagens não encontram senão os discursos relativos à sua pessoalidade. Em linguagem simples: tal encontro não representa o momento em que o gênio, enfim humanizado, poria às claras os procedimentos de confecção do próprio pensamento. Muito ao contrário. A humanização de Will, ao afastá-lo das convenções dos papéis sociais (ele não quer a afamada medalha Fields do professor Gerald Lambeau), constitui uma maneira silenciosa, mas não menos eficiente, de enfeudar a figura do gênio em um solipsismo que implode a totalidade das pontes de interlocução entre ele a as personagens à sua volta. Blindado por essa soberba que se traveste de humildade e que torna autônoma e inconsciente a forma final do produto de seu pensamento, o gênio indomável pode refugiar-se na alegação da

seu colo e observou-o ofegar seu último suspiro olhando para você pedindo ajuda. Se eu lhe perguntasse sobre amor, você provavelmente citaria um soneto, mas você nunca olhou para uma mulher e se sentiu totalmente vulnerável (...) Eu olho para você e não vejo um homem inteligente, confiante. Eu vejo um garoto arrogante, assustado. Mas você é um gênio, Will. Ninguém nega isso. Ninguém poderia compreender as profundezas de você (...) Você é um órfão, certo? Você acha que eu sei a primeira coisa sobre o quão difícil sua vida tem sido - como você se sente, quem você é - porque eu li Oliver Twist? Isso encapsula você? Pessoalmente, eu não dou a mínima para tudo isso. Porque, sabe que mais, se eu não posso aprender nada com você, não posso ler numa porra de um livro. A menos que você queira falar sobre você, quem você é. Aí eu fico fascinado. Estou dentro. Mas você não quer fazer isso, quer? Você está com medo do que você pode dizer. 
impossibilidade de partilha dos meios de produção da usina simbólica que serve de motor de suas experiências intelectuais.

É preciso tocar o sino para o fato de a independentização das capacidades do gênio nem sempre ser obrada pela ausência de filiação. O filme também apela à negativização dos saberes socialmente adquiridos por intermédio do aburguesamento do gesto da citação, tipificado na figura do menino rico de Harvard, ricaço que utiliza passagens de livros - sem as declarar - no rebaixamento do amigo de Will, Chuckie. Will, então, toma a frente do debate e, explicitando, com direito a citações de página, a origem livresca dos dizeres que pareciam brotar da boca do adversário, destroça o lugar de suposto saber no qual o rapaz endinheirado pretendia se arvorar. Pois bem, a vilanização quase caricata daqueles que se reportam a saberes cuja origem é externa faz com que percamos de vista que as pretensões de saber do jovem burguês são muito mais vulneráveis e passiveis de serem postas em xeque do que a humilde genialidade do jovem Will, genialidade que, sem outro cimento que não as fronteiras da individualidade do gênio, mantém-se oclusas, não consentindo qualquer alternativa.

Tudo termina bem. O deficiente psicológico, uma vez ajustado aos protocolos de conduta de uma sociabilidade sem violência e a um futuro financeiro visivelmente assegurado, parte em busca da mulher amada, não sem antes se despedir da única figura a quem reconhece certa dívida: o psicólogo.

\section{Billy Elliot}

Nos últimos dois filmes analisado, a deficiência a ser superada desloca-se definitivamente do gênio para as personagens que o cercam. Não é mais a deficiência física ou psicológica que ameaça o voo do gênio. São os preconceitos sociais. E é contra eles que Billy Elliot se tem de debater. Isso não significa, em absoluto, que se imponha dicotomia simples entre a pureza de Billy e o atraso de sua família. Seu pai, Jackie Elliot, e seu irmão, Tony Elliot, são indiretamente responsáveis pela emergência do acesso de Billy ao balé. É por conta da greve dos mineiros, na qual seu pai e seu irmão se envolvem, que as aulas de balé, até então realizadas em local à parte dos meninos, passam a ladear às de boxe. Se a greve é estratégia de luta que visa abalar a ordem do trabalho, seus efeitos não se reduzem à inversão das relações de poder entre patrões e empregados. A greve atinge o conjunto do corpo social e questiona as distribuições e compartimentalizações dos papeis sociais, especialmente pela aproximação de realidades que, em regime normal de socialização, nunca despontariam avizinhadas, à moda do balé e do boxe. Pela primeira vez, à família e ao especialista é anexo o papel das coletividades na definição do destino do gênio. Pela primeira vez, o enfrentamento contra a ordem vigente, cujo expoente máximo é aqui a polícia, deixa de ser uma conduta desviante que exigiria a intervenção de um psicólogo, convertendo-se em princípio ético de resistência. 
A ausência de dicotomias simples se evidencia ainda quando os preconceitos ecoarem no próprio modo com que o jovem aspirante à bailarino vê-se a si. Finda a sua primeira aula de balé, Billy confessa à professora Mrs. Wilkinson que se sente «sissy» durante o bailado. Acontece que, à contramão de Will, o jovem aprendiz monta um sistema de referenciação que lhe auxilia a guerrear contra impasses e dilemas, interiores e exteriores. Note-se que sua primeira atitude, após assumir o desafio de se tornar bailarino às escondidas do pai, consiste em roubar um livro de balé. Portanto, o desafio só é suportado porque Billy, não obstante os sermões paternos acerca da incompatibilidade entre a masculinidade e o balé, sabe de cor uma máxima materna - «be yourself» -, máxima registrada em uma carta que Billy lê para Mrs. Wilkinson, momentos antes de iniciar a preparação da sua primeira apresentação de balé, embalada pela música I Love to Boogie, gravada em uma fita cassete surrupiada do irmão. Em tempo: se Billy tem a feição de uma concha de retalhos composta por múltiplas vozes e acontecimentos sociais de proveniências diversas, se não há preocupação em fazer dele um solo demiúrgico, é porque o arco da genialidade de Billy jamais se volta nunca retesado em direção ao esmagamento do outro. Dançando balé, ele não pretende ser melhor do que a professora, que sequer dança; não quer ser melhor do que o melhor amigo gay; tampouco melhor do que seus familiares; nem mesmo do que os policiais que, em vez da gravata do advogado do, vestem cassetetes. Billy quer dançar e atingir um ponto de ebulição tal que seu corpo, convertido em «electricity», possa voar, até desaparecer, como ele o diz para uma das juradas ao encerrar a apresentação no Royal Ballet Scholl.

O tom piegas dessa declaração apaixonada de Billy pelo balé indica a enorme diferença entre a representação cinematográfica do perfil de Will e a de Billy. Nesta forma de representação, o gênio aponta para a irrevogável dissolução de sua pessoa (não sem antes ter exibido o passo a passo que o levou a posição de dançarino); naquela, desaparecem os processos de constituição do lugar de matemático brilhante (restando apenas uma modalidade de presença caracterizada pela dureza da impenetrabilidade da pessoalidade do gênio humanizado). Recapitulando, pois, a fim de pormenorizar: o momento em que Billy sapateia não sobre o pai, mas para o pai na noite de natal, a fim de demonstrar suas habilidades, à semelhança do balé que Brow executava com o giz entre os dedos do pé esquerdo diante da família, nada tem que ver com encadear hierarquias entre os que sabem e os que não sabem dançar, mas com a possibilidade de criar no espectador alguma disposição de acolha diante do que talvez lhe provoque excessiva estranheza - como é o caso da substituição dos sapatos de boxe por sapatilhas de balé. E estranho não é o mesmo que desconhecido. Os pais de Brown e de Billy percebem aquilo que seus filhos têm a exibir. Os filhos pintam, dançam. Os filhos não escrevem números e algarismos que apenas transformariam seus progenitores, isto é, seus espectadores, em ignorantes. O balé de Billy e as pinturas de Brown não produzem a ignorância alheia, simplesmente convidam o outro para acomodar a eclosão do inesperado. O resultado da trajetória de Billy é o aparecimento de uma competência social específica que abdica de todo mistério, já que o que está em jogo não é a pessoa de Billy, mas o artista, ainda que não deixe de haver uma permanente coafetação entre as diferentes categorias de ser que o constituem - amigo, filho, aluno etc.

Clandestinas são apenas as aulas. Tanto no filme Meu pé esquerdo quanto em Billy Elliot, os espaços de aprendizagem são pouco institucionalizados. Brown desenvolve suas habilidades em casa, e, quando é arrastado ao hospital, depressa volta à casa da família. Por sua vez, a rotina de treinos de Billy é abrigada em uma academia de boxe, onde Billy balia sobre o ringue. No entanto, exceto no filme Gênio Indomável, isso não 
implica aversão ao jogo ensino/aprendizado, não desemboca na intransmissibilidade das técnicas de produção de um saber-fazer específico, mas apenas na taxativa recusa à alegada insofismável partilha ente aptidões e competências, ou, o que vem a dar no mesmo, na recusa dos pareceres das autoridades que pretendem determinar de antemão os que podem (e os que não) dedicar-se a esta ou aquela atividade.

A bordo do diagnóstico dos médicos, Brown estaria fadado a uma vida vegetativa. À luz dos dizeres do pai de Billy, o garoto deveria concentrar-se no boxe, no futebol, ou no wrestling, já que a disposição para a dança estaria congenitamente afeita às aptidões femininas. No entanto, nem um dos dois filmes se opõe ao destino previsto pelos discursos oraculares elaborados pelas expertises por meio da atribuição de dons inatos aos seus protagonistas. Brown tem enorme dificuldade em escrever a primeira palavra com o pé. Nas primeiras aulas de balé, Billy é tudo menos um peixe dentro da água. É atrapalhado, desengonçado, incapaz de acompanhar as garotas mais novas que dançam ao seu lado. E a ideia de que «he might be a fucking genius», expressa pelo pai do garoto, é apenas a fantasia de alguém que não acompanhou o processo de produção de tais habilidades. Portanto, secreto, nesses dois filmes, não é o conjunto de operações cognitivas e de rotinas de aprendizagem, são os minúsculos bolsões sociais nos quais se viabiliza a suspensão da fixação prévia e indelével do lugar social das personagens. Se Tony Elliot acorre de madrugada ao combate a favor dos grevistas, se Billy e Brown começam seus treinos fora dos holofotes institucionais, isso nada tem que ver com problemas psicológicos, e sim com a criação de vias alternativas às autoestradas das mundividências consensuais.

Há um único ponto em que as representações das figuras de Will e Billy dão-se as mãos. Billy não era fisgado pelo balé por intermédio da violência. Mrs. Wilkinson não tinha de apanhá-lo pela jugular para ganhar sua atenção, à semelhança da conduta do psicólogo Sean diante de Will, como se a violência, ainda que pontual, quando aplicada às personagens pobres, funcionasse como uma espécie de função fática sem a qual a comunicação estaria obstaculizada. Contudo, o filme não deixa de insistir na ideia de haver uma natural oposição entre arte e violência. E isso de duas maneiras. A primeira delas: vigora a violência entre os que não pertencem ao universo da arte (o pai de Billy chega a dar um soco no rosto do filho mais velho). Mas, ainda mais importante, o filme veicula o pressuposto de a suspensão da arte, mesmo entre os praticantes, acarretar imediatamente a violência. Logo depois de Billy dizer a Mrs. Wilkinson que não consegue realizar certo movimento e sair esbravejando do ringue, os dois trocam ferroadas, até que ela bate no garoto. Do mesmo modo, quando Billy dá um soco no colega no vestiário do Royal Ballet Scholl, é porque imagina que fracassou na avaliação, quer dizer, imagina que está fora do mundo da arte.

Por que razão haveria algo de perigoso nessa antinomia entre arte e violência, afinal? Ora, a paixão de Billy pela arte em nada se aproxima a uma sublimação de comportamentos sociais tidos como desviantes, apenas com a paixão de dançar. Se o fim último de Billy fosse tornar-se ajustável às expectativas sociais (trabalhar, amar, ou, no mínimo abrir mão da violência), o boxe, que não é senão uma forma de violência regrada, circunscrita, contida, teria bastado. Acontece que a força de Billy advém de não tomar a arte no sentido de mero meio de adestramento de si, mas como fim em vista do qual mobiliza suas energias vitais, exatamente o que fazia Brown, quando explodia de violência, mordendo e arrastando com a boca a toalha de mesa do restaurante, justamente depois da sua primeira exposição pública de quadros, recusando, desta feita, 
a fusão entre o pertencimento ao mundo da arte e a pacificação dos comportamentos. Portanto, é curioso notar como os filmes que não representam a arte como meio de combate das mazelas sociais e que, nesta medida, abrem o flanco para serem vilipendiados como defensores da arte pela arte, às vezes oferecem uma representação das relações entre as personagens e o saberes muito mais democráticas do que os filmes que fazem da arte o remédio balsâmico das injustiças sociais.

Nas últimas cenas de Billy Elliot, depois de encenadas as despedidas (Billy despede-se da avó, do irmão, do pai e do amigo), ao reencontrarmos o garoto já crescido, não fazemos a mais remota ideia se ele, por meio da arte, casou-se, amou ou enriqueceu, sabemos apenas que, bailarino profissional, Billy nunca deixou de dançar.

\section{Encontrando Forrester}

De modo idêntico a Will, Jamal Wallace é pobre, vive no Bronx, com o agravante de ser negro, malgrado agora não haver um, mas dois gênios. No mesmo bairro periférico de Jamal, mora William Forrester, um dos maiores escritores do século XX. Tudo se passa como se as determinações geniais antes reunidas em personagens individuais se desdobrassem em duas personagens. E é por intermédio da personagem de William que o filme decola.

O escritor de origem escocesa é extremamente solitário, recluso, sem amigos para pernoitar em bares, sem familiares, exceto os cultivados em antigos álbuns de retrato. Há anos, William não põe os pés para lá da soleira da porta de casa, observando o mundo exterior com uma câmera de vídeo, o que the vale a pecha, cunhada por Jamal e seus amigos, de the window. Há mais de vinte anos que William tem o telefone desligado. Assim, outra vez, o gênio precisa aprender a falar. De novo, uma vida apegada aos livros vem descrita como uma forma de mediação que afasta as personagens de uma vida plena. O que fica claro pelo contraste, desenhado nas primeiras cenas, entre o velho escritor solitário, rodeado de livros, que vê o mundo por meio de um vidro, e o contato corpo-a-corpo do grupo de jovens que joga basquete em frente à sua casa, grupo no qual Jamal se destaca. E destaca-se não apenas como excelente jogador de basquete, mas também como alguém dotado de capacidades intelectuais acima da média, o que logo vem à tona, porque o garoto negro de 16 anos atinge uma nota excepcional no teste da escola pública onde estuda, ganhando passaporte para uma escola privada. Muito embora siga os passos de Will, a genialidade de Jamal é módica, discreta. Quando ficamos a saber, pela boca da professora da escola pública, do desempenho de Jamal na avaliação, também tomamos conhecimento de ele não haver contado para a mãe a respeito de seus feitos escolares. Algumas cenas adiante, Jamal reforça seu comedimento, pedindo ao irmão que não espalhe a notícia. Ora, como vimos, a representação da genialidade é inseparável do esmagamento do outro, ainda que os ataques que partem do gênio sejam sempre justificados pela defesa de si e do outro. 
Ao contrário do Gênio Indomável, agora a figura do advogado não está mais no tribunal; presta serviços ao escritor William. Ao aproximar-se da BMW do advogado, que a estaciona perto da quadra de basquete, Jamal tenta preveni-lo: «l will not do anything with your car». E o advogado responde-Ihe com uma violência cordial: não se trata de preconceito, mas «who knows something about this company knows it's more than just a car». Só então Jamal reage e esbanja a superioridade de seu saber: esmiúça a história da fundação da empresa, informação que o advogado desconhecia. Mas, sem sombra de dúvida, o esmagamento do professor da escola privada para a qual Jamal se encaminha domina a trama. Descrito como uma espécie de duplo mais velho e institucionalizado do menino de Harvard com quem Will pelejava no bar, o professor Crawford, temido por todos os alunos, que há muito sofrem com sua opressão tirânica - a mola legitimadora da intervenção de Jamal -, sentirá a ferocidade da genialidade de Jamal. Diante da humilhação de um colega, que se desorienta no instante de responder a pergunta posta pelo professor, Jamal sai em defesa do oprimido, rebatendo a

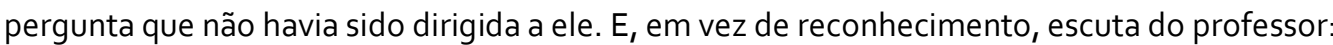

Robert Crawford: Perhaps your skills do not reach farther than basketball.

Jamal: Further.

Robert Crawford: What?

Claire Spence: Don't.

Jamal: You sad that my skills reached "farther" than basketball. "Farther" relates to distance, "further" is a definition of degree. You should have said "further".

Robert Crawford: Are you challenging me, Mr. Wallace?

Jamal: Not more than you challenged Coleridge.

Robert Crawford: Perhaps the challenge should have been directed elsewhere. ${ }^{6}$

Tem início, então, um duelo entre professor e aluno que mimetiza, em larga medida, os programas americanos de perguntas e respostas, certamente uma das imagens, hoje em voga, daquilo que seria o trabalho do pensamento:

6 Tradução:

Robert Crawford: Talvez suas habilidades não cheguem mais distante do que o basquete. Jamal: Longe.

Robert Crawford: O quê?Claire Spence: Não.Jamal: Você disse que minhas habilidades não chegam «mais distante» do que o basquete. «Distante» refere-se a distância, «longe» é uma definição de grau. Você deveria ter dito «longe».Robert Crawford: Você está me desafiando, Mr. Wallace? Jamal: Não mais do que você desafiou o Coleridge.Robert Crawford: Talvez o desafio devesse ter sido direcionado para outro lugar. 
Robert Crawford: «lt is a melancholy truth that even...»

Jamal: «... great men have poor relations». Dickens.

Robert Crawford: "You will hear the beat of...».

Jamal: Kipling:

Robert Crawford: «All great truths Begin...».

Robert Crawford: Shaw.

Jamal: «Man is the only animal...»

Robert Crawford: «... that blushes or needs to». That's Mark Twain. Come on, Professor Crawford.

Robert Crawford: Get out.7

A mesma atitude de esmagamento é praticada por William ao longo do filme. Ele é a tal ponto poderoso que, na cena em que o advogado aparece trazendo as meias do escritor, aquele se ajoelha diante deste (que está majestosamente sentado em um sofá), em clara atitude de subserviência, copiando à risca a atitude servil do professor Gerald Lambeau diante do gesto piromaníaco de Will. William também explicita continuamente sua superioridade diante dos críticos, aqueles que não fariam «in a lifetime» o que ele realizou tão jovem, escrevendo uma obra prima aos 23 anos. Acresce ainda que se vangloria o escritor escocês pelo fato de manter-se no topo da lista dos livros mais lidos, mesmo transcorrido tantos anos após sua primeira publicação, dando a entender que a qualidade de uma obra seja conferivel por sua capacidade de inalterar-se best seller. Indubitavelmente, o coroamento do poder de William consubstancia-se nas cenas finais, quando o escritor afamado decide montar uma armadilha para o professor Crawford. Subitamente, o velho lobo das letras aparece na escola de Jamal, e, com a permissão do professor, simula a leitura de um texto de sua autoria, para revelar, ao final das palmas dos alunos e dos elogios do professor Crawford, que o texto pertence, na verdade, ao garoto jovem, negro e pobre.

Novamente, o que ganha o primeiro plano não é, pois, a obra, mas o poder do gênio consagrado em detrimento do professor vilanizado. No momento em que o escritor começa a leitura em voz alta do texto cuja autoria não lhe pertence, ouve-se uma trilha sonora que cessa somente ao fim da leitura. Não sabemos nada a respeito do conteúdo do texto lido, como também restávamos às escuras no que dizia respeito à obra prima de William. A bem dizer, desde a primeira cena em que Jamal rabisca pensamentos soltos no pequeno bloco

7 Tradução:

Robert Crawford: «É uma verdade melancólica que mesmo ...»Jamal: «... grandes homens têm relações pobres». Dickens. Robert Crawford: «Você vai ouvir a batida de ....»Jamal: Kipling:

Robert Crawford «Todas as grandes verdades começam ....».Jamal: Shaw. Robert Crawford: «O homem é o único animal ...»Jamal: «... que ruboriza ou precisa ruborizar». Isto é Mark Twain. Vamos, Professor Crawford. Robert Crawford: Fora. 
de anotações guardado na mochila no armário da escola pública, não tínhamos acesso àquilo que o garoto escrevia. O que víamos constantemente e de maneira demorada eram as habilidades de Jamal jogador de basquete - quer na cena dos arremessos livres durante o acirrado treino na escola privada, quer na cena dos jogos oficiais, nunca as de Jamal escritor. Quando muito, escutávamos dedilhados de Jamal sobre a máquina de escrever. Duvidássemos dessa genialidade sem obra visível, não pairaria o risco de nos sentirmos excessivamente próximos do racismo do professor, da personagem que duvida das capacidades intelectuais de Jamal?

Ao contrario dos espectadores, o professor teve acesso aos escritos de Jamal. Nesse sentido, o filme retoma, em forma de crítica, a partilha entre aptidões e competências, com a diferença de que substitui os preconceitos em torno do gênero pelos raciais e classistas. É William quem o diz, ao afirmar que "Crawford cannot understand how a black kid from the Bronx can write the way you do». E é também William que o incentiva a demonstração, por meio da escrita, do engodo do professor que acredita piamente ter em mãos o critério que the assessoraria distinguir prévia e cabalmente o alcance das asas de Jamal. No entanto, o filme acaba por justificar a mesma lógica que visa pôr em questão. $O$ absurdo das tentativas de fixação antecipada das ligações entre aptidões e competências, o absurdo da definição apriorística entre quais personagens detêm aptidões - ou não - para certas competências, só vale para o gênio, não se aplica aos pobres da escola pública estadunidenses, desprovidos da latência de tesouros. Se o que punha Billy em contato com o balé era a greve dos mineiros, e não a morte da mãe, Jamal começa a labuta de escrita a partir do momento em que se vê confrontado com a ausência paterna. Em uma palavra, o que faz o garoto do Bronx dar início ao processo de escrita não é uma reorganização da vida social e institucional, é um episódio da vida privada, o que significa que a representação das condições de produção da dita genialidade continua a operar por meio da legitimação de mecanismos de rarefação do acesso, na medida em que, se levarmos às últimas consequências o raciocínio aqui em causa, no lugar da greve, a única possibilidade de ampliação do acesso, que não é assim tão desejável, pois sabemos que as pérolas já não correm o risco de afundar com o navio negreiro escolar, passaria pela chacina dos pais da população negra e pobre.

À parte o tom jocoso da sobredita consideração, o certo é que os mecanismos de rarefação inscritos em certas representações do acesso aos saberes se fazem sentir também em outros níveis, nomeadamente no modo de representação da filiação de Jamal aos saberes. De fato, não há no filme em questão o recurso à exclusão de toda e qualquer filiação. No intuito de tirar Jamal do imobilismo, William fornece ao garoto um texto com o qual ele deve começar, copiando-o, estratégia para que o jovem escritor salte «from page one to page two», até que ele encontre suas próprias palavras. Vê-se bem de que modo a filiação do pensamento não é representada como intrínseca ao processo de produção de obras, mas como mera etapa inicial e provisória, a evaporar-se no momento subsequente, quando o garoto for, então, convertido em fonte do próprio discurso. Assim, não há nenhum processo de canibalização dos saberes, apenas um mimetismo temporário que deverá ser paulatinamente substituído por uma total solidão criadora. O que importa frisar é a construção da ideia de o gênio, uma vez atingida a maturidade, não dever criar companhias para o pensamento. Após breve contato com este ou aquele intercessor, o gênio pode e deve livrar-se daquilo que possibilitou o nascimento de sua obra (no caso, Jamal não tem de matar William, pois o mestre morre ao final, não sem antes the deixar uma carta de despedida). 


\section{Considerações finais}

Antes de me despedir, valeria a pena o esboço, em jeito de balanço final, a respeito das diferentes formas de representação do gênio nos filmes abordados, isto é, a respeito das diferentes formas de erotizar os saberes e torná-los atrativos. Grosso modo, o cinema hollywoodiano vem disponibilizando dois tipos de representação do trabalho do pensamento, isto é, dois modos de representação do processo - ou da ausência dele - de aquisição de habilidades.

De um lado, uma primeira forma de representação do gênio, acentuada em filmes como Meu pé esquerdo e Billy Elliot, insiste na ideia de não haver qualquer aptidão enraizada nos sujeitos, nem predisposição inata que os calibrariam de maneira natural e espontânea em direção a certas atividades sociais e que, portanto, a criação de objetos e saberes não estaria refém de determinações físicas ou sociais intransponíveis, proporcionando a nós, espectadores, o ensejo de imaginar que qualquer competência específica pode vir a ser incorporada a contento pelos sujeitos em geral, com a única condição de que eles sejam armados com saberes manipuláveis e passíiveis de serem empregados em rotinas incansáveis de aprendizado. De outro lado, uma representação, saliente em filmes como Gênio Indomável e Encontrando Forrester, do gênio criador entendido como um tipo de ser que, se nem sempre dispensa inteiramente o recurso aos saberes, apesar de invariavelmente os secundarizar em seu processo de produção, antecipa ao primeiro plano o poder de dominação sobre outrem, tendo o triste fim de nos seduzir mais pelo poder de apagamento da alteridade do que por aquilo que ela, a genialidade, produziria.

Assim, o espaço aberto pelo declínio das representações que negativizavam a arte não desembocou na criação de representações do gênio cujo rosto humano teria dinamitado, de uma vez por todos, os bloqueios cognitivos ao acesso de produção de bens simbólicos, já que tal brecha foi sendo recoberta pela representação de uma genialidade apoiada em um aparente igualitarismo antropológico que teria por consequência a ocultação dos enormes efeitos sectários que decorrem da secundarização da tematização dos mecanismos de produção de obras.

Para concluir, diria que o cinema estadunidense inventou e circulou diferentes formas de «erotizar o saber» (FOUCAULT, 2011, p.327), um saber que já não é mais cinza, mas que não se tornou, por isso, menos perigoso, pois seu caráter apetecível, no mais das vezes, requer ora a exclusão de outrem, ora a exclusão dos próprios saberes sociais. Assim, talvez nos apetecesse, para o rumo dos nossos modos de vida, forjar uma espécie de critério, à semelhança do eterno retorno nietzschiano (DELEUZE, 1976, p.16), que, em vez de verificar a objetividade das representações do gênio que circulam no tecido social, estimasse se as representações de que dispomos potencializam - ou não e o quanto - nosso desejo de produzir objetos matemáticos, políticos ou estéticos: o que nos permitiria bailar mais com as nossas ideias, devires Brown, Will, Billy ou Jamal? 


\section{Referências}

A noite dos desesperados. Direção de Sydney Pollack. Produção American Broadcasting Company (ABC), Produção Palomar Pictures 1969.

BENJAMIN, Walter. Magia e Técnica, Arte e Política: ensaios sobre literatura e história da cultura. São Paulo: Editora Brasiliense, 1996.

Billy Elliot. Direção de Stephen Daldry. Reino unido, Working Title Films, 2000.

DELEUZE. Nietzsche e a Filosofia. Rio de Janeiro: Editora Rio, 1976.

Encontrando Forrester. Direção de Gans Van Sant. Columbia TriStar Filmes do Brasil, 2000.

FOUCAULT, Michel. Ditos \& Escritos IV: Estratégia, Poder-Saber. São Paulo: Forense Universitária, 2006.

FOUCAULT, Michel. Ditos \& Escritos VII: Arte, Epistemologia, Filosofia e História da Medicina. São Paulo: Forense Universitária, 2011.

Gênio Indomável. Direção de Gans Van Sant. Miramax Films, 1997.

LAROSSA, Jorge. Tecnologias do eu e educação. In: SILVA, Tomaz Tadeu. O sujeito da educação. Petrópolis: Vozes, 1994 .

Meu pé esquerdo. Direção de Jim Sheridan. Distribuição: Fox. 1989.

NEVES, Kellen Cristina Marçal de Castro. Cinema: a modernidade e suas formas de entretenimento. Revista de História e Estudos Culturais, Uberlândia, v.3, n.4, p.1-16, 2006.

O Crepúsculo dos Deuses. Direção de Billy Wilder. Paramount Pictures, 1959.

O despertar de Rita. Direção de Lewis Gilbert. Reino Unido, Columbia Home Video, 1983.

RAMOS DO Ó, Jorge. O governo de si mesmo. Lisboa: Educa, p.38, 2003.

SMEYERS, P.; DEPAEPE, M. (Eds.). Educational research 3: the educacionalization of social problems. New York: Springer, 2008.

Três dias de Condor. Direção de Sydney Pollack. ProduçãoWildwood Enterprises, 1975. 
VEIGA-NETO, Alfredo. Coisas do governo... In: RAGO, Margareth; ORLANDI, Luiz B.; VEIGA-NETO, Alfredo (org.). Imagens de Foucault e Deleuze: ressonâncias nietzschianas. Rio de Janeiro: DP\&A, 2002. p.13-34.

Vincent \& Theo. Direção de Roberto Altman. Netherlands, Hemdale Film Corporation ,199o.

ZANONI, Fábio. O cinema e o governo dos homens: o terceiro salvador e as políticas de subjetivação postas em funcionamento na contemporaneidade. Linguagens: revista de Letras, Artes e Comunicação, Blumenau, v.6, n.2, p.106-124, mai./ago. 2012.

Recebido em 21/07/2015 - Aprovado em 15/02/2016. 